\title{
ANÁLISIS BIBLIOMÉTRICO DE LOS ESTUDIOS GEOGRÁFICOS DE LA CAZA EN ESPAÑA (1978-2015)
}

\author{
Antoni Barceló Adrover \\ Servei de Caça del Consell de Mallorca. \\ Departament de Geografia. Universitat de les llles Balears \\ barceloadrover@yahoo.es \\ Miquel Grimalt Gelabert \\ Jaume Binimelis Sebastian \\ Departament de Geografia. Universitat de les Illes Balears \\ miquel.grimalt@uib.es
}

\section{RESUMEN}

España es uno de los principales exponentes de la actividad cinegética en el contexto europeo. Así lo refrendan aspectos como el elevado número de cazadores, la gran superficie destinada a aprovechamiento venatorio o el amplio abanico de especies cinegéticas.

La práctica cinegética es motivo de inspiración y producción cultural muy heterogénea, donde sin duda el campo geográfico tiene su parcela. Se plantea un estudio bibliométrico de las publicaciones geográficas sobre caza en España analizando las temáticas de las aportaciones, la evolución temporal de los trabajos, el territorio de referencia, el ámbito editorial y los investigadores más prolíficos. Los estudios examinados se consolidan entorno a la biogeografía, la geografía del ocio y la geografía agraria.

Palabras clave: España, Geografía, caza, bibliografía cinegética.

\section{ABSTRACT}

Spain is one of the leading exponents in hunting in the European context. The high number of hunters, the large surface dedicated to game preserves and the varied representation of big and small game species are some of the main factors that confers this importance.

Fecha de recepción: noviembre 2015.

Fecha de aceptación: enero 2017. 
Hunting inspires an heterogeneous cultural production, where definitively the geographical point of view has to be considered. It's presented a bibliometric study about hunting and geography in Spain. From the selected papers, we analyze the content, the trend over time, the territorial scope, the publication source and the most prolific investigators. In fact, the results are enclosed around biogeography, leisure geography and agrarian geography.

Keywords: Spain, Geography, hunting, game bibliography.

\section{ANTECEDENTES}

La caza, juntamente con la recolección, es una actividad inherente a la especie humana, ya que constituye una fuente primigenia de sustento anterior a la agricultura y la ganadería. Con adaptaciones y cambios ha llegado a nuestros días con un valor de actividad universal, compendio único de entretenimiento, sustento y condición atávica.

Según el último censo publicado por la Federación de las Asociaciones de Caza y Conservación de la Fauna Silvestre de la Unión Europea (FACE, 2010) España cuenta con 980.000 cazadores, lo cual supone un 13,34 \% del total de entre los 36 países de esta asociación internacional. Dentro de la cual, España es el segundo país con mayor número de practicantes después de Francia y por delante del Reino Unido, Italia, Alemania e Irlanda. En base a los datos referenciados, el porcentaje de cazadores en nuestro país en relación a la población total es del 2,21\%, cifra que se sitúa un punto porcentual sobre la media europea $(1,21 \%)$.

Independientemente de las razones históricas, España es un país extremadamente rico en términos de biodiversidad y a la vez un entorno geoestratégico como lugar de paso o de destino de aves migratorias, lo cual refuerza su condición cinegética. En clave sociológica, los países mediterráneos (FACE, 2010 y Bernard, 2009) son regiones con un alto porcentaje de cazadores en relación a la población ya que la caza, a diferencia de otras zonas geográficas, es practicada por todas las clases sociales con independencia del nivel de renta.

Si bien es cierto que la FACE, a partir de datos proporcionados por la Federación Española de Caza, asigna 980.000 cazadores al conjunto de España para el año 2010, la determinación del número exacto de cazadores por comunidad autónoma es tarea ardua. De hecho, la estadística oficial de la caza en España es incompleta, se encuentra dispersa y no es homogénea (Martinez-Jauregui et al., 2011). Considerando que los datos son aproximativos, según el Ministerio de Agricultura, Alimentación y Medio Ambiente del Gobierno de España (2010) en España existen 1.078.852 licencias de caza. Atendiendo a informaciones del 2005 y del 2010 más de la mitad de las licencias de caza españolas (53 \% y 55,52\%, respectivamente) se han expedido en las Comunidades Autónomas de Andalucía, CastillaLa Mancha y Castilla y León. Estas últimas cifras (Rengifo Gallego, 2009) no guardan relación directa con el potencial demográfico de estas tres comunidades meridionales (muy inferior a la mitad del total nacional), aunque sí se puede establecer cierta correspondencia con la superficie y sus potencialidades cinegéticas.

Según el informe La caza en las autonomías (Trofeo, 2010) las licencias de caza descienden poco a poco en toda España. Se apuntan razones como el encarecimiento de la caza y la desaparición de los terrenos libres, los exámenes del cazador y de armas y, sobre todo, una 
falta de relevo generacional y el paso de una sociedad agraria a otra marcadamente urbana. Las grandes ciudades no son el mejor lugar para aficionarse a la caza, y menos con las opciones que existen en la actualidad. En referencia a la disminución de cazadores desde 1985, además de las causas descritas en el citado informe, los cambios en las formas de caza tradicionales desaniman a los cazadores y la actividad cinegética pierde atractivo en los jóvenes en buena medida por los ataques del ecologismo hacia la caza, a la que acusan de práctica contraria a la conservación de la naturaleza (Martínez Garrido, 2009)

En relación a las superficies cinegéticas, en 1986 el porcentaje de superficie nacional sometida a régimen especial (bien para cazar o bien para evitar que se cace) era del 78,69 \% (López Ontiveros, 1991). Para el año 2010, según los datos recogidos en la estadística anual de caza del Ministerio de Agricultura, Alimentación y Medio Ambiente del Gobierno de España, la suma de terrenos cinegéticos es de 31.434.668 ha. No obstante cabe indicar que no se refleja información para las comunidades autónomas de Aragón, Extremadura, Galicia y del Principado de Asturias. En un intento de completar la estadística de terrenos cinegéticos a nivel nacional se han obtenido los datos de Extremadura y de Galicia a partir de la misma fuente anterior pero para el año 2009 y de Aragón y Asturias a partir del informe La caza en las autonomías (Trofeo, 2010). En total, estas 4 comunidades autónomas, disponen de 11.584.743 ha sometidas a régimen cinegético. Así pues, en torno a 43.019.411 ha del territorio español se corresponden con terrenos cinegéticos, lo cual supone un $85,02 \%$ del conjunto.

En términos económicos, las rentas derivadas de la actividad cinegética son importantes, aunque muy difíciles de evaluar. La caza correctamente gestionada se integra dentro del concepto de desarrollo sostenible en el sentido que aprovecha un recurso natural renovable que por sí mismo requiere un medio mínimamente inalterado, genera una bajo impacto, crea rentas directas e indirectas, y socialmente contribuye a evitar el despoblamiento rural. En 1985, un estudio de Metra Seis indicaba que la caza genera 78.963,4 millones de pesetas (sería equivalente en la actualidad a $474.579,59 €$ ) y 15.187 puestos de trabajo. En el 2003 un estudio promovido por la Oficina Nacional de la Caza y elaborado por la Fundación FAES asocia a la caza 2.677.177.508, $51 €$ y más de 15.000 puestos de trabajo directos. En 2012, la caza en España genera 3.635.756.996 € y unos 54.000 empleos (Garrido, 2012).

Finalmente, la diversidad ambiental y faunística española se refleja también en la existencia de un complejo catálogo cinegético compuesto por más de 50 especies a las cuales se asocia un amplio y diverso repertorio de modalidades de caza. Según la estadística anual de caza del Ministerio de Agricultura, Alimentación y Medio Ambiente del Gobierno de España (2010) se realizaron 313.462 capturas de especies de caza mayor (arruí, cabra montés, ciervo, corzo, gamo, jabalí, lobo, muflón, rebeco y otros), 7.374.476 capturas de especies de mamíferos de caza menor (conejo, liebre, zorro y otros) y 12.870.007 capturas de aves (acuáticas y anátidas, avefría, becada, codorniz, córvidos, estornino, faisán, paloma, perdiz, tórtola común, zorzal y otros). En caza mayor, destacan las capturas de jabalí y de ciervo, que representan aproximadamente el $85 \%$ del total de piezas de caza mayor capturadas, mientras que en caza menor sobresalen, por este orden, el conejo, el zorzal, la perdiz, la paloma y la codorniz, que en conjunto también se aproximan al $85 \%$ del total de capturas de especies de caza menor. 


\section{LA CAZA COMO OBJETO DE ESTUDIO GEOGRÁFICO}

La Geografía rural de ámbito anglosajón (escrita en inglés) ha prestado atención a la actividad cinegética, como hilo conductor de algunos estudios, realizados desde ópticas paradigmáticas y metodológicas diversas. Desde el giro cultural y posmoderno, hallamos interesantes incursiones en este campo temático. Así, desde una óptica antropológica, y desde el enfoque cultural que ha dominado en la Geografía Rural Británica, se han estudiado los ritos culturales en Occidente, como es el caso de la caza del zorro en Inglaterra (Woods, M., 2010). Las relaciones de género han sido también abordadas en relación a la caza (Bye, L. M., 2003). Masculinidad y ruralidad, van de la mano, al constatar la perspectiva que los cazadores tradicionales tienen tanto de la nueva caza comercializada de raíz urbana, y también, la aparición de mujeres en el universo de la caza.

Es en el ámbito de los países nórdicos donde la caza ha sido el argumento principal de trabajos sobre los temas del medio ambiente y de las actividades recreacionales y residenciales en el mundo rural. En un estudio (Pitkänen, Kati, Czesław Adamiak, y Greg Halseth, 2014) del cambio experimentado en las comunidades rurales en Finlandia, los autores observan y analizan las diferencias en el tipo de actividades desarrollados durante el tiempo de ocio y recreo, por los habitantes permanentes, y por los propietarios de segundas residencias, por tanto, de estancia temporal. Comprobaron una clara diferenciación muy relacionada con el tiempo y la accesibilidad, siendo la caza una de las actividades que divide a ambos grupos sociales. El desarrollo del turismo natural y de los paisajes de recreación ha dado lugar al desarrollo de un amplio abanico de actividades. Todo ello da lugar a conflictos, entre los cazadores, celosos de los espacios de la caza, como espacios naturales que son, y los propietarios de los mismos, dinamizadores del impulso experimentado por el turismo cinegético (Øian, Hogne, and Ketil Skogen, 2016). También en los países nórdicos (Von Essen, Erica, et al., 2015) ha sido estudiado el nacimiento y expansión de movimientos radicales y populistas de defensa de la desregulación de la caza y de la caza furtiva, como ejemplo de los movimientos de resistencia rurales contra las políticas de conservación de la naturaleza.

Por otra parte, en el año 1982, la revista científica francesa Études Rurales publicó un monográfico, en su número 87-88, dedicado a la caza y a las actividades recolectoras. Aunque las ópticas de análisis son la antropología y la sociología, sí que aporta valiosos artículos de interés conceptual y metodológico para los investigadores españoles como por ejemplo Chasse, Territoire, groupements de chasseurs (Bozon, 1982) o La diffusion de la chasse et la transformation des usages sociaux de l'espace rural (Chamboredon, 1982). Así pues, es muy posible que algunas de las aportaciones que han sedimentado posteriormente en obras de autores españoles estén inspiradas, en sus inicios, en los trabajos elaborados en el país con mayor número de cazadores de Europa.

La práctica cinegética es motivo de inspiración y producción de material científico muy diverso también es España. Atendiendo a sus implicaciones sociales y territoriales, la caza tiene una manifestación espacial y es considerada objeto de estudio de la geografía, lo que conlleva a explicar de forma científica sus distribuciones (López Ontiveros, 1991 a, 1992 a y 1993). De igual modo, su importancia en España hace que su estudio no pueda permanecer al margen de la reflexión del geógrafo y de otros científicos sociales (López Ontiveros, 1994 a). 
En opinión de López Ontiveros (1992 a), la caza dentro de la geografía, para su adecuada comprensión, hay que referirla a tres ámbitos que se complementan entre sí: el natural, el de la geografía del ocio y el de la geografía agraria.

A) En cuanto al primer ámbito, el natural, con preeminencia de los aspectos físicos, se trataría de analizar la adaptación al contexto ecológico de los recursos faunísticocinegéticos, espacios de caza, técnicas y prácticas. En España esta vertiente zoogeográfica, excepto en algunos pocos casos, se encuentra poco desarrollada. No obstante, el campo de estudio es amplio y necesario, bien sea para completar estudios generales o para incidir específicamente en los aspectos que plantean por ejemplo los planes técnicos de caza.

B) La caza en España también se ha analizado desde el prisma de la geografía del ocio tal y como inicialmente lo pusieron de manifiesto autores como López Ontiveros (1981) o Luís Gómez (1988). Resulta incuestionable que la caza ha experimentado, desde finales de los años setenta, un extraordinario desarrollo a consecuencia del carácter recreativo que ha adquirido la sociedad española actual (Martínez Garrido, 1988).

La caza es una actividad de recreación rural, destacando los cotos de caza como paradigma de espacios rurales de ocio. López Ontiveros y Mulero Mendigorri (1997) catalogan cuatro tipos de espacios rurales de ocio atendiendo a su extensión en España: cotos de caza, montes públicos, ríos y embalses, y espacios naturales protegidos. De entre estos, destacan los cotos de caza, tanto por su extensión como por sus amplias repercusiones socioeconómicas, agrarias y medioambientales. Estos aspectos han sido tratados de forma preferente y detallada en publicaciones específicas (López Ontiveros, 1991 a, 1992 a, 1994; Mulero Mendigorri, 1995).

Las causas comunes de la expansión cinegética y de la recreación rural se deben al descenso de horas de trabajo y aumento del tiempo de ocio, así como de pautas más flexibles por las que se rigen éste; aumento de la renta familiar disponible, e incremento de la movilidad tanto por lo que se refiere al desplazamiento hasta los cazaderos como a la movilidad dentro de éstos con el todoterreno (López Ontiveros, 1991a). Complementa estas causas la puesta en práctica de una política de repoblaciones cinegéticas, iniciada en los años cincuenta del siglo Xx y que se prolongaría durante más de dos décadas, culminando con la aprobación de la Ley 37/66 que creó veinte reservas nacionales de caza con una superficie de casi 1.000.000 ha de terrenos cinegéticos (Crespo, 2013).

C) Además, la caza también tiene carácter agrario igual que la agricultura, la ganadería o la silvicultura.

Los acotados se superponen sobre los espacios agrarios, es decir, sobre un mismo escenario rural se practica la caza y se desarrollan actividades agrícolas y ganaderas. No obstante, su impacto es desigual, dependiendo de las condiciones naturales exigidas para el hábitat de las especies cinegéticas y de la posibilidad de otros aprovechamientos y sus rentas (Martínez Garrido, 1988). En este sentido, la caza no sólo podrá abordarse desde una perspectiva de actividad recreativa y de ocio sino también como aprovechamiento de las explotaciones agrarias -ya sea exclusivo o complementario(López Ontiveros, 1992 a). 
En relación a la dualidad ociosa o agraria de la caza en el medio rural, Díaz Moreno (1979) ya plantea esta cuestión: «La caza, fenómeno que está tomando cada vez mayor apogeo e importancia tiene un interés claro en Geografía Rural. Pero ya de entrada, se suscita el problema al considerar su actividad; o resulta ser una actividad complementaria de la agricultura, o por el contrario una actividad a parte, una actividad de ocio. Las dos posturas son perfectamente válidas,...> .

En cualquier caso, tal y como resume López Ontiveros (1992 a) «la geografía cinegética, como segmento de la biogeografía, como parte de la geografía agraria o como manifestación de la geografía del ocio es tarea compleja e interesante, y en España sólo contamos con atisbos e hipótesis interesantes.>>

\section{LOS INICIOS DEL ESTUDIO GEOGRÁFICO DE LA CAZA EN ESPAÑA}

La mayoría de estudios geográficos sobre la caza en España se sitúan a partir del último cuarto del siglo xx, si bien existen trabajos regionales anteriores a esta época que incluyen la caza en apartados más generales, como por ejemplo en las secciones dedicadas a la fauna:

«Esta actividad destructiva, si bien pobre en general en la isla, no es desconocida ni mucho menos en nuestra zona; afecta una serie de especies, perseguidas sobre todo por sus carnes y que se pueden reducir a unos pocos mamíferos, y algunas más aves sedentarias o, especialmente, migradoras.» (Rosselló Verger, 1964).

Sobre la cita anterior, cabe observar que la caza es considerada como una actividad destructiva. Posiblemente este adjetivo viene adquirido atendiendo a la influencia francesa en los trabajos españoles de geografía regional. Autores como Jean Brunhes o Eliseé Reclús critican, a principios del siglo Xx, el carácter destructivo y devastador asociado a los fines utilitarios, comerciales y deportivos de la caza. Incluso Brunhes desarrolla el concepto de Raubwirtschaft (economía de rapiña o de saqueo) introducido anteriormente por el geógrafo alemán Ernst Friedrich y que hacía referencia, aunque fuese de forma metafórica, a la modalidad de explotación de los recursos naturales de un territorio que, atendiendo a su gran intensidad, provocaba inevitablemente la disminución de las riquezas naturales. González Pellejero (1993) desarrolla en la tesis La actividad cinegética en la España Contemporánea: transformaciones sociales y espaciales de un recurso natural esta concepción devastadora de la caza observada por geógrafos franceses tanto en el país galo como en sus colonias. De hecho, esta tesis es la primera que recoge en su título la relación caza- recurso natural-territorio.

En España, los estudios más recientes que se mencionan de aquí en adelante, no siguen esta corriente crítica sobre todo porque la caza está sujeta a una gran cantidad de normativa y por la imposición de los criterios de gestión. Como argumenta Pérez (1991) «Si hubo un tiempo en que estas limitaciones [a la práctica de la caza] provenían de los privilegios de unos pocos, hoy se trata de dar una oportunidad a la Naturaleza, aunque para ello haya que pedir un poco de sacrificio a los aficionados de la caza deportiva; sea en beneficio de los que nos sucedan.>

Los inicios de los estudios integrales de la caza en España desde la perspectiva geográfica se localizan a finales de la década de 1970 en torno a geógrafos de la Universidad de 
Córdoba. En concreto, Valle Buenestado (1978) es el primer geógrafo español que intuye la importancia de la actividad cinegética. Por su parte, Díaz Moreno (1983) en el VI Coloquio de Geografía celebrado en Palma de Mallorca en el mes de octubre de 1979 presenta la comunicación Caza y usos del espacio rural en España. Este enmarca la caza dentro del espacio rural y de sus actividades de ocio.

En los albores de la década de 1980, López Ontiveros (1981) en su comunicación El desarrollo reciente de la caza en España, presenta un diagnóstico y aporta una serie de indicadores de gran valor para la investigación de la caza en nuestro país. En este trabajo, el autor acuña el concepto de Boom Cinegético. Este boom viene caracterizado por el aumento de licencias de caza desde finales de la Guerra Civil, el incremento de terrenos sometidos a régimen especial, el importante significado económico de la caza (López Ontiveros, 1981), aunque también puede considerarse la política de promoción cinegética del régimen franquista desde 1950 hasta la aprobación de la Ley de Caza de 1970 (Crespo, 2013). Dicho trabajo marca el despegue del estudio geográfico de la caza en España.

Mata Olmo (2011) define los inicios de la línea de trabajo y el enfoque de López Ontiveros «Como agrarista de su tiempo, sensible a los nuevos rumbos de un medio rural muy dinámico, frente a las tesis del arcaísmo y el estancamiento, López Ontiveros inició una línea de investigación prácticamente inédita sobre la caza como actividad socioeconómica en las áreas rurales, de proyección nacional y europea, con numerosas publicaciones de referencia, y superadora de enfoques meramente deportivos, y de planteamientos maniqueos entre partidarios y detractores de esa actividad ancestral.>

El rumbo marcado por López Ontiveros es seguido por un grupo de geógrafos y geógrafas de diferentes universidades españolas, de entre las cuales destacan la Universidad de Córdoba, la Universidad de Extremadura, la Universidad Autónoma de Madrid, la Universidad de Jaén, la Universidad de Oviedo y la Universidad de las Islas Baleares que estructuran diferentes frentes de avance en la temática cinegética. Las principales líneas de investigación son geografía de la caza, turismo cinegético, derivaciones agrarias de la caza y conflictos actuales de la caza (López Ontiveros y Mulero Mendigorri, 1997).

Por su interés geográfico y originalidad, cabe mencionar la clasificación sobre los espacios cinegéticos hispanos (López Ontiveros y García Verdugo, 1991) realizada a partir de cinco indicadores: licencias de caza, piezas de caza mayor capturadas, peso de la caza capturada, cotos privados y renta generada por la caza. Según los resultados obtenidos se agrupan las comunidades autónomas en demandantes y ofertantes en términos cinegéticos. Así, aparecen Castilla-La Mancha y Extremadura como ofertantes de caza, y Aragón y Castilla-León con tendencia a serlo. Andalucía es uno de los principales productores de caza, si bien con un importante equilibrio entre oferta y demanda. Por otra parte, Galicia, Asturias, País Vasco, La Rioja, Cataluña, Madrid, Valencia y Murcia son demandantes netos, y Cantabria, Navarra, Illes Balears y Canarias son comunidades con tendencia a serlo o mal definidas. Los autores reconocen que la geografía cinegética, desde el punto de vista físico, coincide con la Iberia silícea y montañosa de la Meseta y sus rebordes y, también, con el monte y maquis mediterráneo. Pero, desde el punto de vista del medio humano, se circunscribe con las zonas más despobladas por el éxodo rural. No obstante, también insisten en afirmar que los resultados obtenidos no son suficientes para conocer la geografía española de la caza, lo cual sólo será posible cuando se disponga de un mapa 
completo de cotos, se reflexione conjuntamente sobre los aspectos físicos y humanos que la condicionan y se estudien los flujos de cazadores entre comunidades y provincias demandantes y ofertantes.

\section{ESTUDIO BIBLIOMÉTRICO DE LAS PUBLICACIONES GEOGRÁFICAS SOBRE LA CAZA EN ESPAÑA}

El estudio de la actividad cinegética en las publicaciones geográficas se ha realizado con la elaboración del corpus bibliográfico del tema, para después analizar desde una óptica bibliométrica la producción científica en este campo.

Los criterios seguidos para seleccionar las publicaciones son:

I. Que los trabajos estén firmados geógrafos o geógrafas a título individual, en coautoría o en colaboración con investigadores de otras disciplinas.

II. Que el tema principal de estudio sea la actividad cinegética.

Las principales fuentes de consulta han sido:

I. Revistas del área temática geográfica incluidas en el catálogo DICE (Difusión de la Calidad Editorial de las Revistas Españolas de Humanidades y Ciencias Sociales Y Jurídicas). http://dice.cindoc.csic.es/index.php

II. Actas de los Coloquios de Geografía Rural del grupo de geografía rural de la Asociación de Geógrafos Españoles.

III. Artículos de referencia similares al estudio planteado y su bibliografía asociada, concretamente López Ontiveros et al (1990) y Sarmiento (1991).

IV. Revista Agricultura y Sociedad núm. 58 (Gómez -dir.-, 1991), monográfico dedicado al estudio de la caza en España y la bibliografía asociada a las comunicaciones.

V. TESEO (Base de Datos de Tesis Doctorales). https://www.educacion.gob.es/teseo/irGestionarConsulta.do

VI. DIALNET (uno de los mayores portales bibliográficos del mundo, cuyo principal cometido es dar mayor visibilidad a la literatura científica hispana, sobre todo en los ámbitos de las Ciencias Humanas, Jurídicas y Sociales). https://dialnet.unirioja.es/

VII. GOOGLE ACADÉMICO (buscador de Google enfocado especializado en literatura científica-académica). https://scholar.google.es/

Con esta búsqueda, complementada con el seguimiento bibliográfico de los principales autores sobre la materia objeto de estudio, se han localizado un total de 150 publicaciones sobre geografía y caza en España, comprendidas entre 1978 y 2015. A continuación, se ofrece la clasificación temática, temporal, por ámbito geográfico, por fuente de publicación y por autoría de las publicaciones seleccionadas. En el apartado de bibliografía se encuentran clasificadas según su temática, y al final de la referencia bibliográfica aparecen unas siglas que definen el ámbito territorial de referencia y la fuente de publicación. Es preciso indicar que algunas obras o artículos pueden haber quedado al margen del presente análisis, no por su interés geográfico, sino 
debido a la gran dispersión de fuentes bibliográficas, ámbito de estudio local o por ya haber sido catalogadas en recopilaciones de ámbito autonómico como es el caso de Barceló (2013).

\section{IV.I. Distribución temática de las publicaciones}

Las temáticas definidas son las siguientes (tabla 1):

a) Obras de conjunto. Son publicaciones consideradas de referencia sobre el estudio geográfico de la caza en España. Son trabajos que abarcan períodos temporales amplios y generalmente comprenden todo el estado español, aunque en algunos casos pueden centrarse en territorios más reducidos. En términos generales estas publicaciones son de consulta obligada y constituyen el marco conceptual y bibliográfico de referencia. Se asignan a este apartado un total de 17 títulos.

b) Geografía de las especies cinegéticas. Son trabajos elaborados en torno a las especies faunísticas de caza menor y mayor en España. Contienen referencias a las características de estas especies, hábitats, cazaderos, modalidades y técnicas de caza. La geografía relativa a la fauna cinegética dispone de 10 títulos.

c) Caza y geografía agraria. Son investigaciones centradas en la transformación del espacio rural con vistas a mejorar el rédito cinegético, considerando el espacio cinegético como una explotación agraria. Se incluyen aquí aspectos relacionados con la ordenación y explotación de cotos, gestión de especies, cercados, paisajes cinegéticos, propiedad de tierras y desarrollo rural. Estos aspectos forman el contenido de 64 títulos.

d) Geografía de los espacios cinegéticos. Son aportaciones sobre cuestiones sociales y/o territoriales de la actividad cinegética y aluden principalmente a la caza desde el punto de vista recreativo. El marco de estudio es fundamentalmente regional. Los trabajos de esta índole incluyen, entre otros contenidos, estudios generales sobre la caza en una comunidad o región, referencias históricas al aprovechamiento cinegético, indicadores sociales, territoriales y económicos de la caza (número de cazadores, licencias, densidad y tipos de cotos, beneficios económicos, etc.), y asociacionismo cinegético. Este apartado cuenta con 46 títulos.

e) Turismo cinegético. Es una materia asociada a la definida como caza y geografía agraria, aunque con características propias. El turismo cinegético incluye las actividades que realizan las personas que viajan a un lugar determinado atraídas por el recurso caza. En este sentido, son considerados en estos trabajos la procedencia y las características de los turistas, los servicios que se ofrecen, los espacios que visitan, las piezas que se demandan y las rentas que genera esta actividad. Este argumento cuenta con 13 títulos.

Cabe decir que hay algunas aportaciones que bien podrían clasificarse en más de una temática. En estos casos, se ha procedido a analizar su marco conceptual con el objeto de determinar su contenido principal o dominante.

La mayor parte de las publicaciones estudiadas muestran correspondencia con la temática agraria (42,67 \% del total), la línea de investigación de mayor tradición en la geografía española. En este sentido, la mayor parte de los trabajos seleccionados estudian las 
transformaciones llevadas a cabo en el medio para lograr el incremento de la producción cinegética y suplir o complementar las rentas agrarias. En segundo lugar, se sitúan las publicaciones sobre geografía los espacios cinegéticos $(30,67 \%$ del total) donde examinan las características sociales y territoriales de la caza en un marco regional concreto. A continuación, se posicionan las publicaciones de conjunto (11,33\% del total), que comprenden tramas diversas pero de interés general. Los trabajos sobre turismo cinegético ocupan el cuarto lugar $(8,67 \%$ del total) que estudian la movilidad que la caza genera cuya repercusión en el ámbito turístico, económico y social puede ser muy importante. Finalmente, la geografía de las especies cinegéticas $(6,67 \%$ del total) cierra la lista temática (Figura 1).

Tabla 1

TEMÁTICA DOMINANTE EN LA PUBLICACIONES SOBRE GEOGRAFÍA Y CAZA

(1978 - 2015)

\begin{tabular}{|c|c|}
\hline Temática & $\mathbf{N}^{\mathbf{0}}$ de publicaciones \\
\hline Obras de conjunto & 17 \\
\hline Geografía de las especies cinegéticas & 10 \\
\hline Caza y geografía agraria & 64 \\
\hline Geografía de los espacios cinegéticos & 46 \\
\hline Turismo cinegético & 13 \\
\hline Total & $\mathbf{1 5 0}$ \\
\hline
\end{tabular}

Fuente: elaboración propia.

\section{Temática}

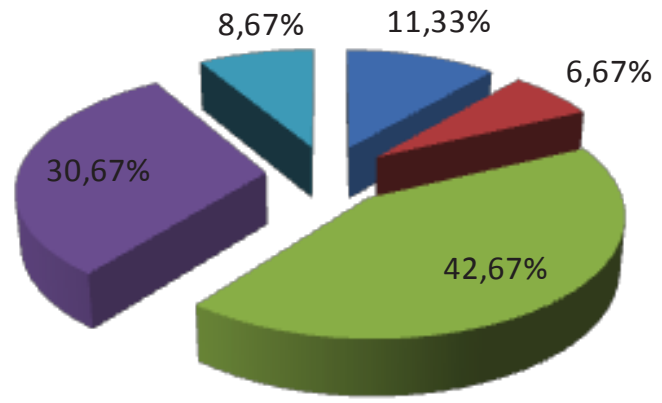

Obras de conjunto

- Geografía de las especies cinegéticas

Caza y geografía agraria

- Geografía de los espacios cinegéticos

Turismo cinegético

Fuente: elaboración propia. 


\section{IV.2. Distribución temporal de las publicaciones}

Las publicaciones examinadas se sitúan en el período comprendido entre finales de la década de 1970 y el año 2015 (tabla 2).

Tabla 2

RELACIÓN TEMPORAL DE LAS PUBLICACIONES SOBRE GEOGRAFÍA Y CAZA (1978 - 2015)

\begin{tabular}{|c|c|c|c|c|c|}
\hline Años & Publicaciones. & Años & Publicaciones. & Años & Publicaciones \\
\hline 1978 & 1 & 1990 & 3 & 2003 & 6 \\
\hline 1979 & 0 & 1991 & 24 & 2004 & 3 \\
\hline 1980 & 0 & 1992 & 3 & 2005 & 3 \\
\hline 1981 & 1 & 1993 & 5 & 2006 & 4 \\
\hline 1982 & 1 & 1994 & 3 & 2007 & 4 \\
\hline 1983 & 5 & 1995 & 2 & 2008 & 3 \\
\hline 1984 & 4 & 1996 & 2 & 2009 & 6 \\
\hline 1985 & 3 & 1997 & 4 & 2010 & 5 \\
\hline 1986 & 5 & 1998 & 1 & 2011 & 4 \\
\hline 1987 & 6 & 1999 & 2 & 2012 & 2 \\
\hline 1988 & 6 & 2000 & 1 & 2013 & 7 \\
\hline \multirow[t]{2}{*}{1989} & 6 & 2001 & 2 & 2014 & 7 \\
\hline & & 2002 & 3 & 2015 & 3 \\
\hline Total & & & & & 150 \\
\hline
\end{tabular}

Fuente: elaboración propia.

Como ya se ha apuntado, el inicio de las publicaciones temáticas sobre geografía y caza se fija en 1978. Aunque el verdadero despegue se sitúa en torno a 1983, hasta alcanzar un máximo a principios de la década de 1990. Concretamente, en el año 1991 la revista Agricultura y Sociedad en su núm. 58, publicó un monográfico sobre caza con alta participación del colectivo de geógrafos. Asimismo, del 30 de setiembre al 2 de octubre de 1991 también se celebra el VI coloquio de geografía rural que incluye una subponencia temática sobre caza, completada con ocho comunicaciones.

Posteriormente, hay un descenso cuantitativo generalizado de publicaciones. Paradójicamente, a partir de ese momento aparecen las primeras tesis doctorales sobre caza en España (González Pellejero, 1993; Mulero Mendigorri, 1993; Martínez Garrido, 2000; Bajo Cuadrado, 2006; Crespo, 2013 y Barceló, 2015). Entre 1994 y 2010, sólo en dos años, 2003 y 2009, se publican hasta seis trabajos sobre geografía cinegética, alcanzando así cotas como en el período precedente. En los años 2013 y 2014 se produce un repunte respecto al período anterior, con siete publicaciones cada uno. Tras despuntar durante dos años, la producción bibliográfica cae hasta sólo 3 publicaciones en el último año de estudio (Figura 2). 
Figura 2

AÑO DE PUBLICACIÓN DE LAS REFERENCIAS BIBLIOGRÁFICAS SOBRE GEOGRAFÍA Y CAZA (1978 - 2015)

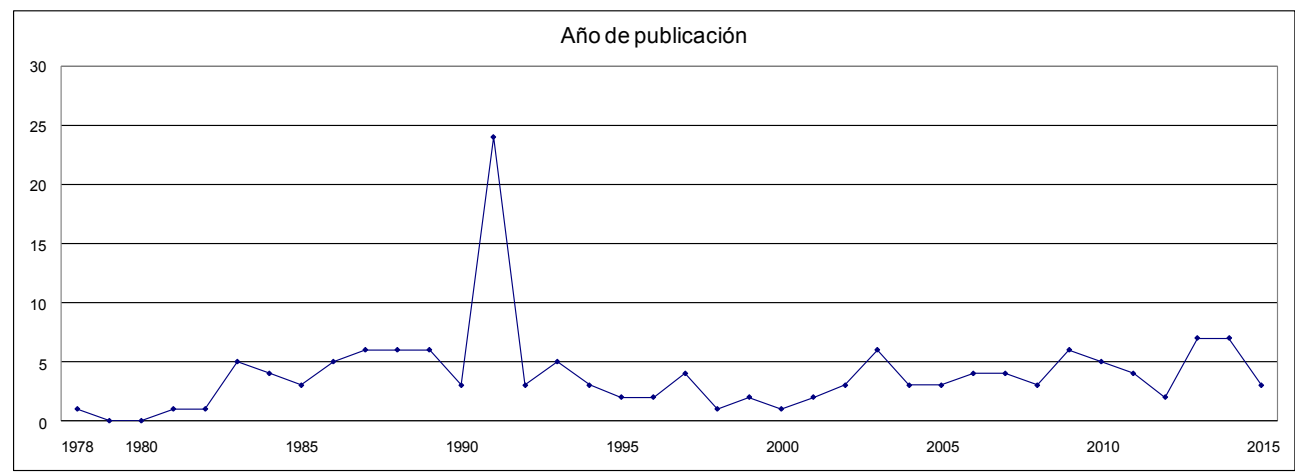

Fuente: elaboración propia.

\section{IV.3. Ámbito territorial}

Entendimos que la comunidad autónoma a la cual se refieren los trabajos es su ámbito territorial. Cierto es que existe un numeroso grupo de estudios que abarcan el conjunto nacional. En este caso se opta por clasificarlos en la categoría más general denominada España (Tabla 4).

\begin{tabular}{|c|c|}
\hline Ámbito territorial & Número de publicaciones \\
\hline España - ESP & 44 \\
\hline Andalucía - And & 44 \\
\hline Castilla -La Mancha - CLM & 17 \\
\hline Illes Balears - IB & 17 \\
\hline Extremadura - Ext & 14 \\
\hline Asturias - Ast & 7 \\
\hline Madrid - Ma & 2 \\
\hline Castilla y León - CL & 1 \\
\hline Galícia - Gal & 1 \\
\hline Murcia - Mur & 1 \\
\hline País Valenciano - Cval & 1 \\
\hline País Vasco - PV & 1 \\
\hline TOTAL & $\mathbf{1 5 0}$ \\
\hline
\end{tabular}

Fuente: elaboración propia. 
La mayor parte de trabajos geográficos sobre caza (29,33\% del total) tienen como ámbito de referencia territorial al conjunto español, aunque, en numerosas ocasiones, el contenido de estas publicaciones está focalizado hacia ámbitos territoriales del mediodía peninsular. Por comunidades, destaca sobremanera Andalucía (29,33\% del total) seguida por CastillaLa Mancha (11,33\% del total), Illes Balears (11,33\% del total) y Extremadura (9,33\% del total). A distancia se encuentran las comunidades de Asturias (4,67\% del total) y Madrid (1,33\% del total). Con valores mínimos aparecen las comunidades de Castilla León, Galicia, Murcia, País Vasco y País Valenciano (todas con 0,67 \% del total). No se tiene constancia de trabajos geográficos específicos sobre la caza en Aragón, Canarias, Cantabria, Cataluña, Navarra, La Rioja ni en las ciudades autónomas de Ceuta y Melilla (Figura 3).

Figura 3

ÁMBITO TERRITORIAL DE REFERENCIA DE LAS PUBLICACIONES SOBRE GEOGRAFÍA Y CAZA (EN \%) (1978 - 2015)

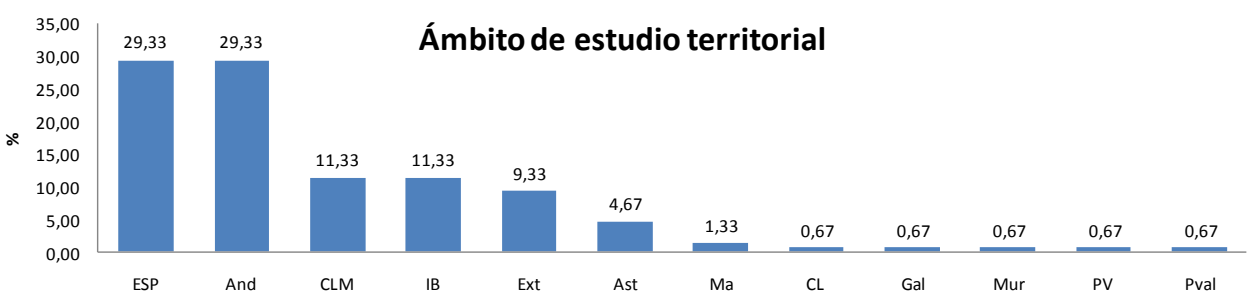

Fuente: elaboración propia.

En efecto, existen comunidades estudiadas de forma exhaustiva, pero retomando las palabras de López Ontiveros (1992 a) «hay muchas comunidades autónomas sobre las que no sabemos nada al respecto.>>

Si comparamos los datos actuales con los estudios bibliográficos de Sarmiento (1991) y López Ontiveros (1992 a) que también ofrecen un recuento por comunidades, se puede observar como la evolución de estudios y trabajos geográficos sobre caza ha aumentado considerablemente. Sarmiento (1991) recuenta treinta y siete títulos repartidos entre nueve comunidades autónomas y una categoría general referida al conjunto español (Tabla 5). López Ontiveros (1992 a) contabiliza treinta y ocho títulos sobre caza escritos por geógrafos y geógrafas en publicaciones científicas (Tabla 6).

Tabla 5

DISTRIBUCIÓN TERRITORIAL DE LOS PRINCIPALES ARTÍCULOS SOBRE

GEOGRAFÍA DE LA CAZA EN ESPAÑA SEGÚN SARMIENTO (1991)

\begin{tabular}{|c|c|}
\hline Ámbito territorial & Artículos \\
\hline Aspectos generales de la caza en España & 7 \\
\hline Andalucía & 12 \\
\hline Castilla-La Mancha & 5 \\
\hline Extremadura & 4 \\
\hline
\end{tabular}




\begin{tabular}{|c|c|}
\hline Castilla y León & 2 \\
\hline Cataluña & 2 \\
\hline Comunidad Valenciana & 2 \\
\hline Galicia & 1 \\
\hline Asturias & 1 \\
\hline Illes Balears & 1 \\
\hline Total & $\mathbf{3 7}$ \\
\hline
\end{tabular}

Fuente: elaboración propia a partir de Sarmiento (1991)

Tabla 6

DISTRIBUCIÓN TERRITORIAL DE LA BIBLIOGRAFÍA SOBRE CAZA SEGÚN LÓPEZ ONTIVEROS (1992 a)

\begin{tabular}{|c|c|}
\hline Ámbito territorial & Artículos \\
\hline Aspectos generales de la caza en España & 16 \\
\hline Andalucía & 9 \\
\hline Castilla-La Mancha & 4 \\
\hline Extremadura & 5 \\
\hline Galicia & 1 \\
\hline Asturias & 2 \\
\hline Illes Balears & 1 \\
\hline Total & $\mathbf{3 8}$ \\
\hline
\end{tabular}

Fuente: elaboración propia a partir de López Ontiveros (1992 a)

En ambos casos, destaca el elevado número de publicaciones referentes al conjunto de la geografía española, aunque a nivel regional, las comunidades de Andalucía, Castilla-La Mancha y Extremadura destacan muy por encima de todas las demás. La evolución hasta la actualidad ha sido, en este sentido, proporcional excepto en el caso de Illes Balears dónde el impulso administrativo a la caza, junto con el posterior apoyo del Departamento de Geografía de la UIB, ha sido determinante en el incremento de su producción bibliográfica (Barceló, 2013).

\section{IV.4. Fuente de publicación}

Se han establecido cinco categorías para las fuentes de publicación de los trabajos revisados. Las fuentes consultadas se han desglosado en tesis doctorales, libros (se incluyen aquí los Diplomas de Estudios Avanzados), revistas científicas, obras colectivas (aportaciones a congresos, coloquios, seminarios o jornadas, capítulos de libros, capítulos de tesis y enciclopedias, básicamente) y revistas temáticas (revistas específicas del sector cinegético) (Tabla 7). 
Tabla 7

FUENTE DE PUBLICACIÓN DE LAS REFERENCIAS SOBRE GEOGRAFÍA Y CAZA (1978 - 2015)

\begin{tabular}{|c|c|}
\hline Fuentes & $\mathbf{N}^{\mathbf{0}}$ de publicaciones \\
\hline Tesis & 6 \\
\hline Libro & 19 \\
\hline Revista & 50 \\
\hline Obra colectiva & 62 \\
\hline Revista temática & 13 \\
\hline Total & $\mathbf{1 5 0}$ \\
\hline
\end{tabular}

Fuente: elaboración propia.

Las dos principales fuentes de publicación son las obras colectivas $(41,33 \%$ del total) y las revistas científicas (33,33\% del total). En conjunto representan casi el $75 \%$ del total. En el capítulo de las obras colectivas destacan las aportaciones en los congresos y coloquios de geografía rural, mientras que en el ámbito de las revistas científicas destaca especialmente el monográfico sobre caza núm. 58 de Agricultura y Sociedad del año 1991. La mayor parte de estos trabajos se han presentado en obras colectivas y revistas nacionales, mientras que sólo seis pertenecen al ámbito internacional (principalmente publicaciones en revistas o trabajos franceses). A continuación y con un peso similar destacan los libros $(12,67 \%$ del total $)$ y los artículos en revistas temáticas $(8,67 \%$ del total). Finalmente, se localizan las tesis (4\% del total). Concretamente, de las seis tesis doctorales, cinco son monográficas sobre la actividad cinegética (González Pellejero, 1993; Martínez Garrido, 2000; Bajo, 2006; Crespo, 2013 y Barceló, 2015) mientras que una (Mulero Mendigorri, 1993) presenta un contenido más amplio e incluye otras temáticas sobre recreación rural (Figura 4).

Figura 4

FUENTE DE PUBLICACIÓN DE LAS REFERENCIAS SOBRE GEOGRAFIA Y CAZA (1978 - 2015)

Fuente de publicación
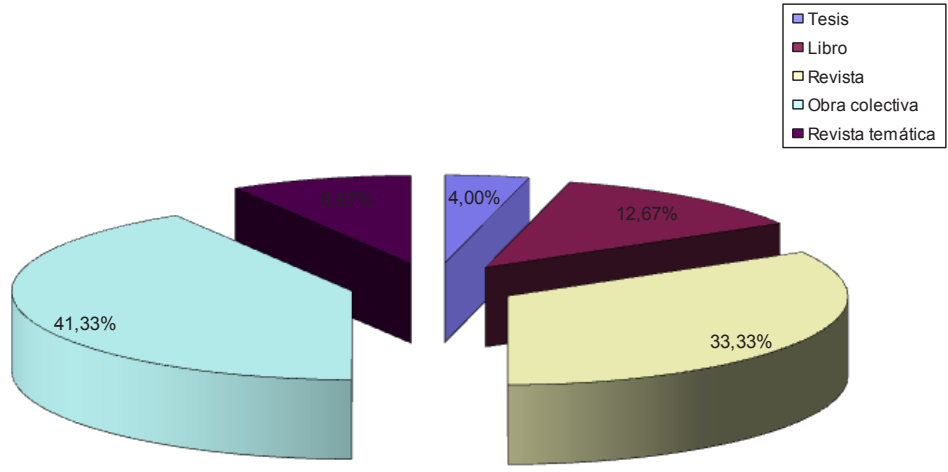

Fuente: elaboración propia. 


\section{IV.5. Producción por autores}

Las 150 publicaciones recopiladas han sido elaboradas por 71 personas diferentes (Tabla 8).

Tabla 8

PRODUCCIÓN POR AUTORES (1978 - 2015)

\begin{tabular}{|c|c|c|c|c|c|}
\hline Autor & pub. & Autor & pub. & Autor & Pub. \\
\hline López Ontiveros & 28 & Rios-Saldaña & 2 & Melchor & 1 \\
\hline Martínez Garrido & 27 & Vargas & 2 & Moraleda & 1 \\
\hline Mulero & 15 & Vidal & 2 & Naranjo & 1 \\
\hline Barceló & 15 & Villafuerte & 2 & Obiol & 1 \\
\hline Araque & 13 & Aguiló, J. A. & 1 & Ocaña & 1 \\
\hline Rengifo & 10 & Arroyo & 1 & Ortega & 1 \\
\hline Crespo & 10 & Balsera & 1 & Ortigosa & 1 \\
\hline Alvarado & 8 & Bover, P. & 1 & Osuna & 1 \\
\hline Valle & 8 & Campos & 1 & Palmer, M. & 1 \\
\hline Cecília & 6 & Cantero & 1 & Pérez & 1 \\
\hline Seguí & 6 & Cañadilla & 1 & Pons, G. X. & 1 \\
\hline Fernández & 5 & Castelló, M. & 1 & Rivera & 1 \\
\hline Sánchez, J.D. & 5 & Cooke & 1 & Sánchez & 1 \\
\hline García, F & 4 & Delibes-Mateos & 1 & Sánchez Urrea, J. & 1 \\
\hline Bajo & 3 & Díaz & 1 & Sánchez, M.A. & 1 \\
\hline Moya & 3 & Doctor & 1 & Sánchez, M.J. & 1 \\
\hline Binimelis & 2 & Gallego, V.J. & 1 & Santandreu & 1 \\
\hline Brunet & 2 & Garcia, A & 1 & Sanz & 1 \\
\hline García Amengual, A & 2 & García, B & 1 & Serrano & 1 \\
\hline Garrido & 2 & García, E.L & 1 & Silva & 1 \\
\hline Grimalt & 2 & Garzón & 1 & Torija & 1 \\
\hline Leco & 2 & Gómez & 1 & Urzainki & 1 \\
\hline Sarmiento & 2 & González & 1 & Utanda & 1 \\
\hline Castro & 2 & Manera, J. & 1 & & \\
\hline
\end{tabular}

Fuente: elaboración propia.

Antonio López Ontiveros es el geógrafo que ha participado en mayor número de publicaciones con veintiocho (18,67 \% del total), seguido por Emilia Martínez Garrido con veintisiete (18,00\% del total) y Alfonso Mulero Mendigorri y Antoni Barceló Adrover con quince $(10,00 \%$ del total). Eduardo Araque ha participado en trece publicaciones $(8,67 \%$ del total), Juan Ignacio Rengifo Gallego y José Manuel Crespo en diez publicaciones $(6,67$ $\%$ del total), Eduardo Alvarado Corrales y Bartolomé Valle Buenestado en ocho (5,33\% del total), Jesús Ángel Cecilia y Bartomeu Seguí en seis (4,00 \% del total), Felipe Fernández y José Domingo Sánchez en cinco (3,33 \% del total), Francisco R. García Verdugo en 
cuatro (2,67 \% del total) y Froilán Bajo y Egidio Moya en tres (2,00 \% del total). Jaume Binimelis, Pere Brunet, José Manuel Crespo, Ángel García Amengual, Antonio Garrido, Miquel Grimalt, Felipe Leco, María Eugenia Sarmiento, Francisca Castro, Carlos Antonio Ríos-Saldaña, Juan Mario Vargas, Javier Vidal y Rafael Villafuerte han firmado dos publicaciones $(1,33 \%$ del total para cada autor/a), respectivamente. Los cuarenta y tres investigadores/as restantes han participado en sólo una publicación (que en su conjunto supone un 28,67\% del total)

Analizando los datos anteriores, los/as autores/as que han participado en más del $5 \%$ de las referencias bibliográficas estudiadas pertenecen a las Universidades de Córdoba (López Ontiveros, Mulero Mendigorri y Valle Buenestado), Autónoma de Madrid (Martínez Garrido), Jaén (Araque y Crespo), Extremadura (Rengifo Gallego y Alvarado Corrales) e Islas Baleares (Barceló), y han centrado sus estudios principalmente en las comunidades de Andalucía, Castilla-La Mancha, Extremadura y Baleares. Estos nueve autores han intervenido en prácticamente el $80 \%$ del total de las obras estudiadas.

\section{CONCLUSIONES}

Las obras y títulos analizados previamente ponen de manifiesto que la caza es una actividad geografía en España. No obstante, los estudios son recientes y la importancia de estos trabajos es relativa, en comparación con el peso que se le da en otras disciplinas científicas, como también en relación a las temáticas y/o líneas de investigación propias de la geografía.

Por una parte, si se analizan las tesis registradas en el sistema de gestión de tesis doctorales a nivel nacional (TESEO) que contengan en el título las palabras caza, cazador, cinegético/a o venatorio/a, caça, caçador, cinegètic, cinegètica, venatori y venatòria resulta que aparecen ochenta y seis aportaciones. De éstas, sólo cuatro (4,65\% del total) pertenecen a la geografía. Concretamente, son las tesis de Martínez Garrido (2000), de Bajo Cuadrado (2006), de Crespo (2013) y de Barceló (2015). Es preciso indicar que en la base de datos no aparecen las tesis de González Pellejero (1993) ni de Mulero Mendigorri (1993), si bien en esta última no aparece en el título palabra alguna del campo semántico citado.

Por otra parte, si se indaga en los títulos de ponencias y comunicaciones presentadas en los dieciséis coloquios de geografía rural celebrados entre 1980 y 2014, se localiza una subponencia, diecisiete comunicaciones y un póster temático en relación directa con la caza. Especial importancia tuvo, como se ya se ha dicho anteriormente, el VI Coloquio de Geografía Rural celebrado en 1991 en la Universidad Autónoma de Madrid con la subponencia Aprovechamiento y gestión de la caza en España de Antonio López Ontiveros, con ocho comunicaciones. Las demás comunicaciones sobre caza en los Coloquios de Geografía Rural se reparten de la siguiente manera:

- 2 comunicaciones en el IV Coloquio de Nacional de Geografía Agraria (La Laguna, 1987).

- 2 comunicaciones en el VIII Coloquio de Geografía Rural (Jaca, 1996).

- 1 comunicación en el XI Coloquio de Geografía Rural (Santander, 2002).

- 1 comunicación en el XIII Coloquio de Geografía Rural (Baeza, 2006) 
- 2 comunicaciones en el XV Coloquio de Geografía Rural (Cáceres, 2010).

- 1 comunicación y 1 póster temático en el XVII Coloquio de Geografía Rural (Girona, 2014).

Ya fuera del período de análisis del presente trabajo (1978 - 2015), se han localizado diversos artículos (Rengifo y Sánchez, 2016; Crespo, en prensa a y b) que reflejan la continuación de los estudios geográficos sobre caza en los espacios más prolíficos en este sentido, localizados en la mitad Sur peninsular.

Considerando la dimensión social y territorial de la actividad cinegética en España, su estudio, en general, queda lejos de ser una temática geográfica fecunda en cuanto a publicaciones, debido a la irregularidad temporal de los trabajos y a la inexistencia de líneas de investigación claras y continuadas.

En su conjunto, la caza en España se posiciona como una temática con entidad secundaria en geografía, ya que su investigación es relativamente escasa teniendo en cuenta que mueve más de un millón licencias y que más de $4 / 5$ partes del territorio nacional están sometidas a régimen cinegético. La caza está presente en el medio rural y actúa como poderoso acicate para conservar hábitats y especies, y como actividad recreativa contribuye de manera importante a las economías rurales.

En los países europeos con altos índices de actividad cinegética, académicamente existen estudios y líneas de investigación geográfica al respecto.

La Ley 45/2007, de 13 de diciembre, para el desarrollo sostenible del medio rural comprende acciones y medidas de desarrollo rural sostenible. Esta Ley considera la importancia de la caza y la gestión sostenible de la fauna cinegética en el desarrollo de los Programas de Desarrollo Rural Sostenible. De hecho, el Real Decreto 752/2010, de 4 de junio, por el que se aprueba el primer programa de desarrollo rural sostenible para el período 2010-2014 en aplicación de la mencionada ley alude a la caza como un recurso importante en el medio rural y la incluye en sus ejes estratégicos y medidas del programa. Concretamente, la caza es incluida en el eje 1 sobre actividad económica y empleo y en el eje 4 sobre medio ambiente. En la mayoría de los actuales programas de desarrollo rural autonómicos (2014 - 2020), la caza juega un papel relevante como herramienta de desarrollo para generar riqueza y empleo basándose en la materialización del principio de complementariedad entre medio rural y medio urbano y en cuanto a la conservación de la naturaleza y la gestión de los recursos naturales.

Ante esta perspectiva, la geografía dispone en la caza de una oportunidad de estudiar un entorno fértil debido a su alta transversalidad con otras temáticas rurales, ya sea desde el punto de vista físico o humano. Además, la mayoría de fuentes primarias de información sobre la actividad (registros de licencias de caza, expedientes de cotos, planes técnicos de caza, etc.) están poco estudiadas. Igualmente, en la mayoría de comunidades españolas, son relativamente escasos los precedentes sobre catalogación de elementos patrimoniales asociados a la caza, los análisis del perfil social del cazador, el estudio del asociacionismo cinegético, el conocimiento de las modalidades y especies cinegéticas en su conjunto, la exploración de los paisajes venatorios, la relación entre caza y conservación, la evaluación del turismo cinegético o la definición de comarcas cinegéticas, entre otros asuntos de relevancia geográfica. 
En cualquier caso, uno de los frentes menos estudiados, posiblemente por las múltiples dificultades que plantea, es el análisis del componente económico generado en torno a la caza. Sin embargo, las estimaciones sobre la renta cinegética en un territorio, junto con la aportación de datos sobre licencias de caza o número total de cazadores y la superficie total de espacios cinegéticos, se consolidan como cimientos fundamentales a la hora de diseñar estudios que combinen geografía y venatoria.

En conclusión, son muchas las ópticas de aproximación al conocimiento científico de la caza. La comunidad geográfica dispone aquí de un interesante campo de estudio, tanto desde el punto de vista de investigación académica como desde la planificación y gestión aplicada, pública o privada.

\section{BIBLIOGRAFÍA}

\section{Leyenda}

\begin{tabular}{|l|l|}
\hline Ámbito territorial de referencia & Sigla \\
\hline España & ESP \\
\hline Andalucía & And \\
\hline Castilla-La Mancha & CLM \\
\hline Extremadura & Ext \\
\hline Asturias & Ast \\
\hline Illes Balears & IB \\
\hline Madrid & Ma \\
\hline Galicia & Gal \\
\hline Castilla León & CL \\
\hline País Valenciano & PVal \\
\hline Murcia & Mu \\
\hline País Vasco & PV \\
\hline
\end{tabular}

\begin{tabular}{|l|l|}
\hline Fuente de publicación & Sigla \\
\hline Tesis doctoral & $\mathrm{T}$ \\
\hline Libro & $\mathrm{L}$ \\
\hline Revista científica & $\mathrm{R}$ \\
\hline Obra colectiva & Oc \\
\hline Revista temática & $\mathrm{Rt}$ \\
\hline
\end{tabular}

\section{Obras de conjunto (17 títulos)}

BARCELÓ, A. (2013) «Bibliografia cinegètica mallorquina: una visió des de la Geografia». Boll. Soc. Hist. Nat. Balears, 56: 137-164. IB / R 
DÍAZ MORENO, J. (1983) «Caza y usos del espacio rural en España» en VI Coloquio de Geografía (Asociación de Geógrafos Españoles). Palma de Mallorca, Universidad de Palma de Mallorca, 347-355. Esp / Oc

GÓMEZ, J. y LÓPEZ ONTIVEROS, A. (2001) «Montes y caza» en Geografía de España (Gil, A. y Gómez, J., coord.). Barcelona, Editorial Ariel. 405-424. Esp / Oc

GONZÁLEZ PELLEJERO, R. (1993) La actividad cinegética en la España Contemporánea: transformaciones sociales y espaciales de un recurso natural. Tesis doctoral. Departamento de geografía, urbanismo y ordenación del territorio. Universidad de Cantabria. Esp / T

LÓPEZ ONTIVEROS, A. (1986) «Caza y actividad agraria en España y Andalucía. Su evolución reciente» Agricultura y Sociedad, 40: 67-98. And / R

LÓPEZ ONTIVEROS, A. (1989) «La obra de A. Chapman y W. J. Buck» en La España Inexplorada (Chapman, A. y Buck, W.J.). Sevilla, Consejería de Obras Públicas y Transportes y Patronato del Parque Nacional de Doñana. xix-xiv. Esp / Oc

LÓPEZ ONTIVEROS, A. (1991 a) «Algunos aspectos de la evolución de la caza en España» Agricultura y Sociedad, 58: 13-51. Esp / R

LÓPEZ ONTIVEROS, A. (1992 a) «La investigación sobre la actividad cinegética en España: Estado de la cuestión» en VI Coloquio de geografía rural. Ponencias (Asociación de Geógrafos Españoles. Grupo de Trabajo de Geografía Rural) Madrid, Universidad Autónoma. 145-188. Esp / Oc

LÓPEZ ONTIVEROS, A., VALLE BUENESTADO, B., SARMIENTO, M. E. y MULERO MENDIGORRI, A. (1990) Bibliografía Cinegética de España y Andalucía. Sevilla, Instituto Andaluz de Reforma Agraria. 144 pp. ESP / L

LÓPEZ ONTIVEROS, A. y GARCÍA VERDUGO, F. R. (1991) «Geografía de la Caza en España» Agricultura y Sociedad, 58: 81-112. Esp / R

LÓPEZ ONTIVEROS, A. y MULERO MENDIGORRI, A. (1997) «Síntesis de la investigación reciente sobre recreación rural en España (1960 - 1995)» Agricultura y Sociedad, 83: 77-115. ESP / R

LÓPEZ ONTIVEROS, A. y MULERO MENDIGORRI, A. (1997) «Recreación rural y caza en España» en La investigación hispano-británica reciente en geografía rural: del campo tradicional a la transición postproductivista. (López Ontiveros, A. y Molinero, F., coord.). Murcia, Asociación de Geógrafos Españoles, 215-227. ESP / Oc

MARTÍNEZ GARRIDO, E. (2000) La caza en la provincia de Ciudad Real: su análisis geográfico como aprovechamiento reciente. Tesis doctoral. Departamento de Geografía, Universidad Autónoma de Madrid. 3 vol. CLM / T

MARTÍNEZ GARRIDO, E. 2009. «Visiones territoriales del boom cinegético español, 1970 - 1989» Boletín de la Asociación Española de Geógrafos, 51: 325-351. ESP/ R

MULERO MENDIGORRI, A. (1993) Espacios rurales de ocio. Significado general y análisis en la Sierra Morena cordobesa. Tesis doctoral. Universidad de Córdoba. And / T

RENGIFO GALLEGO, J. I. (2010 c) «Caza y turismo cinegético como instrumentos para la conservación de la naturaleza» Anales de Geografía de la Universidad Complutense, vol. 30, 2: 163-186. Esp / R

SARMIENTO, M. E. (1991) «Bibliografía cinegética española» Agricultura y Sociedad, 58: 397-427. Esp / R 


\section{Geografía de las Especies Cinegéticas (10 títulos)}

ARROYO, F. (1991) «Caza y fauna en Castilla La Nueva en el Siglo xvi según las relaciones topográficas de Felipe II». en Actas del VI Coloquio de Geografía Rural. (Asociación de Geógrafos Españoles. Grupo de Trabajo de Geografía Rural). Madrid, Universidad Autónoma de Madrid.183-196. CLM / Oc

CECILIA, J. A. y MARTÍNEZ GARRIDO, E. (1998) La caza del jabalí en España. Barcelona, Hispano Europea. 384 pp. Esp / L

BAJO CUADRADO, F. (2001) «La acción contra las fieras en Asturias en los siglos XVIII y XIX» (Nota bibliográfica) Ería, 56: 324 - 327. Ast / R

LÓPEZ ONTIVEROS, A. (1995) «Gredos y la Capra Hispánica» en Gredos: Territorio, Sociedad y Cultura. (Troitiño, M.A., coord.). Ávila, Diputación Provincial de Ávila. 173 - 202. CLM / OC

MARTÍNEZ GARRIDO,E. (1983) «El jabalí en la provincia de Guadalajara» Caza y Pesca: 375-377. CLM / Rt

MULERO MENDIGORRI,A. (1989) «Cazadores, piezas y técnicas de caza tradicionales en las Marismas de Doñana» Caza y Pesca, 554: 97-99. And / Rt

ORTEGA, T., SEGuí, B., BARCELÓ, A., PONS, G.X., BOVER, P., PALMER, M. y MANERA, J. (2002) «Estudi alimentari del mart (Martes martes L.) a Andratx (Mallorca, Illes Balears)» Boll. Soc. Hist. Nat. Balears, 45: 197-213. IB / R

RÍOS-SALDAÑA, C. A., CAÑADILLA, J., MARTÍNEZ GARRIDO, E., CASTRO, F., VARGAS, J. M. y VILLAFUERTE , R. (2007) «Rescatando las fuentes de información: las solicitudes de control de conejo en España» en VIII Jornadas de la sociedad Española para la Conservación y Estudio de los Mamíferos (Palomo, L.J., ed.). Huelva, Sociedad Española para la Conservación y Estudio de los Mamíferos. 156. Esp / Oc

RÍOS-SALDAÑA, C.A., DELIBES-MATEOS, M., CASTRO, F., MARTÍNEZ GARRIDO, E., VARGAS, J.M., COOKE, B.D y VILLAFUERTE, R. (2013) «Control of the European rabbit in central Spain» European journal of wildlife research, 59(4) 573-580. CLM / R

SEGUÍ, B., SANZ, A., BARCELÓ, A., GARCÍA, A, SANTANDREU, J. y VIDAL, F.J. (2014) Boc Balear: Cuatro milenios de historia, diez años de homologación. Mallorca. Palma, Editado por el Consell de Mallorca con la colaboración del Capítulo Balear del SCI, del Safari Club Internacional y del El Premio Ullmann para Trofeos Europeos de Caza Mayor. 253 pp. IB / L

\section{Geografía Agraria (64 títulos)}

AGUILÓ, J. A., CASTELlÓ, M., SEGUí, B., BARCELÓ, A., GARCÍA, A. y VIDAL, J. (2011). «Caça i pedra en sec a Mallorca» en V Trobada d'estudi per a la preservació del patrimoni de pedra en sec als Països Catalans (2009). (Reynés, A., coord.). Palma, Consell de Mallorca. 63-76. IB / Oc

ALVARADO CORRALES, E. (1983) «Los espacios rurales y el ocio. Los cotos de caza (Cáceres 1973 - 1983)» en VIII Coloquio de Geógrafos Españoles. Comunicaciones (Asociación de Geógrafos Españoles). Barcelona, Asociación de Geógrafos Españoles. 149-155. Ext / Oc 
ALVARADO CORRALES, E. (1983) El sector forestal en Extremadura. Ecología y economía. Cáceres, Institución Cultural “El Brocense”. Diputación de Cáceres.392 pp. Ext / L

ALVARADO CORRALES, E. (1984) «Fuentes agrarias actuales para el estudio del monte» Norba, 5: 9-50. Ext / R

ALVARADO CORRALES, E. (1984) «La caza en la Sierra de San Pedro: aproximación al estudio de su importancia económica y sus funcionalidades medioambientales» Jara, 6: 31-36. Ext / R

ALVARADO CORRALES, E. (1991) «Socioeconomía de la caza. El ejemplo extremeño» en Manual de ordenación y gestión cinegética. (Fuentes, A., Pajuelo L. y Sánchez, I. coord.). Badajoz, IFEBA,. 21-51. Ext / Oc

ARAQUE, E. (1988) La Sierra de Segura: contribución al estudio de la crisis de la montaña andaluza. Tesis doctoral. Departamento de Análisis Geográfico Regional y Geografía Física. Universidad de Granada. And / T

ARAQUE, E. (2009) «La crisis de los espacios de montaña en Andalucía. Estado de la cuestión» Nimbus: Revista de climatología, meteorología y paisaje, 23: 25-44. And / R

ARAQUE, E. (2012) El Parque Natural de la Sierra de Andújar: uso y gestión territorial. Jaén, Servicio de Publicaciones de la Universidad de Jaén. And / L

ARAQUE, E., CANTERO, J. M., GARRIDO, A., MOYA, E. y SÁNCHEZ, J. D. (2005) «Sierra Morena, una lectura geográfica para un destino turístico en Ciernes» Cuadernos de turismo, 16: 7-48. And / R

ARAQUE, E.; SÁNCHEZ, J. D. y CRESPO, J. M. (2007) «Prépondérance de l>activité cynégétique dans le Parc Régional de la Sierra de Andújar (Communauté d>Andalousie, Espagne)». Sud-ouest européen, 23: 127-141. And / R

ARAQUE, E. y MOYA, E. (2008) «La política de conservación de la naturaleza y desarrollo socioeconómico en las sierras de Cazorla, Segura y Las Villas (Jaén)». Ería, 75: 129-142. And / R

ARAQUE, E. y CRESPO, J. M. (2011) «Chasse, conservation de la nature et développement économique dans un espace andalou protégé» Histoire \& Sociétés Rurales, Vol 36 (2) 137-161. And / R

BALSERA, J. y LÓPEZ ONTIVEROS, A. (1986) «El Papel de las actividades cinegéticas: los cotos de caza» en Supervivencia de la Sierra Norte de Sevilla. Evolución de los Paisajes y Ordenación del Territorio en Andalucía Occidental. (Fourneau, F., Roux, B. y Vacher, J. eds.). Madrid, Junta de Andalucía, Ministerio de Agricultura, Pesca y Alimentación, Casa Velázquez. 299-335. And / Oc

BARCELÓ, A. (2002) «Activitat cinegètica i desenvolupament rural» en Geografía y Territorio. El papel del geógrafo en la escala local. (Blázquez, M., Cors, M., González, J. M. y Seguí, M. eds.). Palma, Universitat de les Illes Balears. 325 - 330. IB / Oc

BARCELÓ, A. y GRIMALT, M. (2014) «La huella cinegética en Mallorca. Piedra en seco y gestión de la caza». en. Actas del XVII Coloquio de Geografía Rural (Pavón, D., Ribas, A., Ricart, S., Roca, A., Salamaña, I. y Tous, C. eds.). Girona, Documenta Universitaria. 745 - 758. IB / Oc

CECILIA, J. A. y MARTÍNEZ GARRIDO, E. (1983) «Las cercas y su incidencia en la caza mayor». Trofeo, 162: 29-32. Esp / Rt

CECILIA, J.A. y MARTÍNEZ, E. (1991) «Los cercados eléctricos». Trofeo, 254: 12-17. Esp / Rt 
CRESPO, J.M. (2003 a) El Coto Nacional de Caza de las Sierras de Cazorla y Segura (1960-1986). DEA. Universidad de Granada. AND / L.

CRESPO, J.M. (2003 b) «Repercusiones sociales de los daños producidos por la repoblación cinegética de los años cincuenta en las Sierras de Cazorla y Segura (Jaén)» Cuaderno de la Sociedad Española de Ciencias Forestales, 16: 303-308. And / R

CRESPO, J.M. (2007) «Aprovechamientos cinegéticos en los montes andaluces. Orígenes del coto nacional de caza de las Sierras de Cazorla y Segura (1912-1960)» en Los montes andaluces y sus aprovechamientos: experiencias históricas y propuestas de futuro. (Araque, E. y Sánchez, J.D. coord.). Jaén, Universidad de Jaén. 205-252. And / Oc

DOCTOR, A .M. (1991) «Incendios forestales y caza» Agricultura y Sociedad, 58: 313-325. Esp / R

GALLEGO, V.J., SÁNCHEZ, J.D., CRESPO, J.M. y ARAQUE, E. (2003) «La dehesa de Espeluy: pervivencia de un paisaje excepcional en la campiña andaluza» en La construcción histórica del paisaje agrario en España y Cuba (Sabio, A. y Iriarte, I., eds.). Madrid, Instituto de estudios Altoaragoneses; Universidad de Zaragoza y Los Libros de la Catarata. 147-168. And / Oc

GARCÍA CORBÍ, E.L. (2006) «Actividad cinegética en el campo de Montiel y nuevas dinámicas agrarias provocadas por la PAC» en Actas del XIII Coloquio de Geografía Rural. (Araque, E., Gallego, V.J., Sánchez, J.D. y Valle, B., eds.). Baeza, Asociación de Geógrafos Españoles (Grupo de Trabajo de Geografía Rural). 807-816. CLM / Oc

GARCÍA LÓPEZ, A. (1996) «La caza en la Sierra Norte : Agroindustrias derivadas» en Actas del VIII Coloquio de Geografía Rural. (Frutos, L.M., Hernández, M.L. y De la Riva, J.R., coord.). Zaragoza, Asociación de Geógrafos Españoles (Grupo de Trabajo de Geografía Rural). 639-646. And / Oc

GARCÍA RODRÍGUEZ, B. (1991) «Gestión y conflictos generados por la caza en el monte de El Pardo (1800 - 1931)» en Actas del VI Coloquio de Geografía Rural. (Asociación de Geógrafos Españoles. Grupo de Trabajo de Geografía Rural). Madrid, Universidad Autónoma de Madrid. 197-204. Ma / Oc

LÓPEZ ONTIVEROS, A. (1981) «El desarrollo reciente de la caza en España» en Supervivencia de la Montaña. Actas del coloquio Hispano - Francés sobre las Áreas de Montaña. Madrid, Ministerio de Agricultura y Ministère de l'Environnement et du Cadre de Vie. 271-297. Esp / Oc

LÓPEZ ONTIVEROS, A. (1985) «Chasse et activité agricole en Espagne et en Andalousie : évolution récente» Revue Géographique des Pyrénées et du Sud-Ouest, T 56: 203-223. And / R

LÓPEZ ONTIVEROS, A. (1989) «Evolución de los paisajes cinegéticos andaluces» en Seminario sobre el Paisaje. Debate conceptual y alternativas sobre su ordenación y gestión.(Centro de Estudios Territoriales y Urbanos). Sevilla, Junta de Andalucía, Consejería de Obras Públicas y Transportes. 79-86. And / Oc

LÓPEZ ONTIVEROS, A. (1992 b) «Recursos cinegéticos y desarrollo» en Varios Autores: Desarrollo local y medio ambiente en zonas desfavorecidas (Ministerio de Obras Públicas y Transportes). Cuenca, Universidad Internacional Menéndez y Pelayo. 105122. Esp / Oc 
LÓPEZ ONTIVEROS, A. (1993 a) «Importancia de la geografía cinegética en el contexto de la geografía agraria española» en Medio siglo de cambios agrarios en España (Gil, A. y Morales, A., eds.). Alicante, Instituto de Cultura Juan Gil Albert, Diputación Provincial de Alicante. 191-216. Esp / OC

LÓPEZ ONTIVEROS, A. (1994 a) «Caza, actividad agraria y geografía en España» Documents d'Anàlisi Geogràfica, 24: 111-130. Esp / R

LÓPEZ ONTIVEROS, A. (1994 b) «Vocabulario geográfico y caza» en El medio rural español: cultura, paisaje y naturaleza: homenaje a Don Àngel Cabo Alonso, vol. 1. (Cabero, V., ed.). Salamanca, Universidad de Salamanca. 73 - 78. Esp / Oc

LÓPEZ ONTIVEROS, A., VALLE BUENESTADO, B. y GARCÍA VERDUGO, F. R. (1988) «Caza y paisaje geográfico en las tierras béticas según el Libro de la Montería» en Actas del V Coloquio Internacional de Historia Medieval de Andalucía. Andalucía entre Oriente y Occidente (1236 - 1492). (Cabrera, E., coord.). Córdoba, Excma. Diputación Provincial de Córdoba. 281-307. And / Oc

LÓPEZ ONTIVEROS, A. y VALLE BUENESTADO, B. (dir.). (1989) Caza y explotación cinegética en las provincias de Córdoba y Jaén. Córdoba, Instituto Andaluz de Reforma Agraria. 157 p. And / L

LÓPEZ ONTIVEROS, A. y VALLE BUENESTADO, B. (1989) Estudio sobre las características de la explotación cinegética en las provincias de Córdoba y Jaén. Córdoba, Instituto Andaluz de Reforma Agraria. 157 p. And / L

MARTÍNEZ GARRIDO, E. (1984) «La caza como actividad agraria» Caza y Pesca, 494: 86-88. ESP / Rt

MARTÍNEZ GARRIDO,E. (1984) «La caza como aprovechamiento agrario. Un ejemplo de explotación silvo-agro-pecuario-cinegética: La Almoraima» Caza y Pesca, 499: 442-444. And / Rt

MARTÍNEZ GARRIDO, E. (1987 a) «Los cotos privados de caza de Ciudad Real (I)» Trofeo, 205: 27-30. CLM / Rt

MARTÍNEZ GARRIDO, E. (1987 b) «Los cotos privados de caza de Ciudad Real (y II)» Trofeo, 206: 19-23. CLM / Rt

MARTÍNEZ GARRIDO, E. (1988 a) «Propiedad y regímenes de tenencia en los cotos privados de Ciudad Real» en II Reunión de estudios regionales de Castilla - La Mancha. (Diputación de Ciudad Real, Área de Cultura). Ciudad Real, Diputación de Ciudad Real. 257-273. CLM / OC

MARTÍNEZ GARRIDO, E. (1988 b) «La caza. Un aprovechamiento fuente de riqueza» Caza y Pesca, 549: 587-589. ESP / Rt

MARTÍNEZ GARRIDO, E. (1991) «La geografía de la caza en Castilla-La Mancha» Agricultura y Sociedad, 58: 263-293. CLM / R

MARTÍNEZ GARRIDO, E. (1991) «Los cotos sociales de Castilla - La Mancha: evolución, gestión y explotación» en Actas del VI coloquio de geografía rural. (Asociación de Geógrafos Españoles. Grupo de Trabajo de Geografía Rural). Madrid, Universidad Autónoma de Madrid. 205-220. CLM / Oc

MARTÍNEZ GARRIDO, E. (2010) «Memoria colectiva y lenguaje popular en el control de predadores por la caza» en Lenguajes y visiones del paisaje y del territorio. (Ortega, N., 
García, J. y Mollá, M., coord.). Madrid, Universidad Carlos III, Asociación de Geógrafos Españoles. 349-358. ESP / Oc

MARTÍNEZ GARRIDO, E. (2010) «Caza y custodia del territorio en los paisajes agrarios españoles» en Actas del XV Coloquio de Geografía Rural. Territorio, paisaje y patrimonio rural. (Leco, F., coord.). Cáceres, Universidad de Extremadura, Servicio de Publicaciones. ESP / Oc

MARTÍNEZ GARRIDO, E. y TORIJA, R. (2009) «Los paisajes de la caza de Ciudad Real: Un ensayo de clasificación» en Geografía, territorio y paisaje: el estado de la cuestión. (Pillet, F., Cañizares, M.C. y Ruíz, A.R., coord.). Ciudad Real, Asociación de Geógrafos Españoles. 1161-1175. CLM / Oc

MARTÍNEZ GARRIDO, E. y SÁNCHEZ, J. (2009) «Caracterización actual de los paisajes cinegéticos de la provincia de Albacete». en Geografía, territorio y paisaje: el estado de la cuestión. (Pillet, F., Cañizares, M.C. y Ruíz, A.R., coord.). Ciudad Real, Asociación de Geógrafos Españoles. 1347-1357. CLM / Oc

MARTÍNEZ GARRIDO, E. y SÁNCHEZ URREA, J. (2014) «Los grandes cotos privados de caza de los Montes de Toledo: las paradojas de una montaña media latifundista y mallada» en Atlas de los paisajes agrarios de España, Tomo II. Las unidades de paisaje agrario de la España Mediterránea. (Molinero, F., coord. general). Madrid, Ministerio de Agricultura, Alimentación y Medio Ambiente. Apartado III.2E.Paisajes forestales y de alta montaña. 909-924. And / Oc

MOYA, E. (2004) «La caza» en Los montes públicos en el sur de la provincia de Jaén. (Moya, E.). Tesis doctoral. Universidad de Jaén. 896 - 905. And / Oc

ORTIGOSA, M. (1991) «La caza en tierras de titularidad pública de la provincia de Córdoba» Agricultura y Sociedad: 58, 295 - 309. And / R

MULERO MENDIGORRI, A. (1991) «Ordenación cinegética y conservación de la naturaleza en la provincia de Córdoba» en Actas del VI Coloquio de Geografía Rural. (Asociación de Geógrafos Españoles. Grupo de Trabajo de Geografía Rural). Madrid, Universidad Autónoma de Madrid. 221-228. And / Oc

MULERO MENDIGORRI, A. (2003) «Protección y gran propiedad en Sierra Morena: El Parque Natural de la Sierra de Hornachuelos (Córdoba) como emblemático» Papeles de Geografia: 38, 115-136. And / R

MULERO MENDIGORRI, A. (2013) «El paisaje forestal-cinegético en Sierra Morena: una lectura geográfica» Cuadernos Geográficos: 52, 108 - 128. And / R

MULERO MENDIGORRI, A. (2014) «El paisaje forestal-cinegético de Sierra Morena: Hornachuelos como ejemplo paradigmático» en Atlas de los paisajes agrarios de España, Tomo II. Las unidades de paisaje agrario de la España Mediterránea. (Molinero, F., coord. general). Madrid, Ministerio de Agricultura, Alimentación y Medio Ambiente. Apartado III.2E.Paisajes forestales y de alta montaña. And / Oc

MULERO MENDIGORRI, A. y NARANJO, J. (1996) «Caza y desarrollo rural en la montaña andaluza: fuentes actuales para su estudio» en Actas del VIII Coloquio de Geografía Rural. (Frutos, L.M., Hernández, M.L. y De la Riva, J.R., coord.). Zaragoza, Asociación de Geógrafos Españoles (Grupo de Trabajo de Geografía Rural). 277-289. And / Oc

MULERO MENDIGORRI, A. y SILVA , R. (2013) «Paisajes de Sierra Morena: una cuestión de miradas y escalas» Revista de estudios regionales: 96, 36-64. And / R 
OCAÑA, J. y GARZÓN, R. (2002) «Medio ambiente y ordenación de la caza en Andalucía: cambios e interrogantes» en Los espacios rurales entre el hoy y el mañana: Actas del XI Coloquio de Geografía Rural. Santander, Universidad de Cantabria - Asociación de Geógrafos Españoles. 747-757. And / Oc

RIVERA, M. (1991) «Caza y agricultura en zonas de montaña» Agricultura y Sociedad, 58: 113-145. Ext / R

SÁNCHEZ, J.D., ARAQUE, E., CRESPO, J.M. y GARRIDO, A. (2008) «La repoblación forestal en Sierra Morena, Jaén (1940 - 1984)» Anales de Geografía de la Universidad Complutense, 28 (1) 105-131. And / R

SERRANO, J. M. (1991) «Aprovechamiento de la caza en la región de Murcia. Áreas acotadas, titularidad y distribución espacial» en Actas del VI coloquio de geografía rural. (Asociación de Geógrafos Españoles. Grupo de Trabajo de Geografia Rural). Madrid, Universidad Autónoma de Madrid. 229-238. Mu / Oc

URZAINKI, A. (1991) «La gestión de la caza y el desarrollo rural integrado (el coto social de los montes de la Parzonería General de Guipuzkoa y Álava)» en Actas del VI coloquio de geografía rural. (Asociación de Geógrafos Españoles. Grupo de Trabajo de Geografía Rural). Madrid, Universidad Autónoma de Madrid. 239 - 246. PV / Oc

VALLE BUENESTADO, B. (1978) «Los cotos de caza mayor en la Provincia de Córdoba. Notas para el estudio geográfico» en Actas del V Coloquio de Geografía. (Asociación de Geógrafos Españoles). Granada, Servicio de publicaciones de la Universidad. 589-595. And / Oc

VALLE BUENESTADO, B. (1991) «Aprovechamiento y gestión de la caza en España. Una reflexión a propósito de los cercados cinegéticos» en Actas del VI Coloquio de Geografía Rural. (Asociación de Geógrafos Españoles. Grupo de Trabajo de Geografia Rural). Granada, Servicio de publicaciones de la Universidad. 257-270. ESP / Oc

\section{Geografía de los espacios cinegéticos (46 títulos)}

ALVARADO CORRALES, E. (1990) «La caza en Extremadura. Un recurso poco conocido» Agroexpo, 3: 37-49. Ext / R

ALVARADO CORRALES, E. (1991) «La actividad cinegética en Extremadura» Agricultura y Sociedad: $58,215-240$. Ext / R

ALVARADO CORRALES, E. y SÁNCHEZ, M. A. (1987) «Sierra de San Pedro entre la naturaleza y el hombre» en La caza en Extremadura. I Congreso Internacional de la Caza en Extremadura. Cáceres, Institución Cultural "El Brocense”. Diputación de Cáceres. 253-265. Ext / Oc

ARAQUE, E. (2005) «Las nuevas funciones recreativas de los montes. Reflexiones desde un escenario privilegiado: las Sierras de Segura y Cazorla (Jaén). Cuadernos de turismo: 15, 7-25. And / R

ARAQUE, E. (2007) «Usos y aprovechamientos de los montes de Sierra Morena (Jaén) Pasado y presente» en Los montes andaluces y sus aprovechamientos: experiencias históricas y propuestas de futuro (Araque, E. y Sánchez J.D.). Jaén, Servicio de Publicaciones de la Universidad de Jaén. Jaén. 13 - 58. And / Oc 
ARAQUE, E. Y CRESPO, J. M. (2015) «Reboisements et conflits sociaux dans les monts du sud de l'Espagne: la Sierra de Segura (Jaén)» en Forêt et montagne. (Corvol, A., Dereix, Ch., Gresser, P., y Lormant, F.). Paris, L'Harmattan. 271-284. And / Oc.

BAJO CUADRADO, F. (2006) La Caza en Asturias. Análisis del aprovechamiento geográfico de un recurso natural. Tesis doctoral. Universidad de Oviedo. Ast / T

BARCELÓ, A. y SEGUí, B. (eds) (2006) Societat de Caçadors de s'Horta, 25 anys. Palma, Departament de Medi Ambient i Natura del Consell de Mallorca, Societat de Caçadors de s'Horta, Caça i Medi Natural. 230 p. IB / L

BARCELÓ, A. (2009) La Caça a Mallorca. Palma, Conselleria de Medi Ambient del Govern de les Illes Balears. 175 p. IB / L

BARCELÓ, A. (2011) La caça com a objecte d'estudi de la Geografia: Estat de la qüestió. DEA. Universitat de les Illes Balears. IB / L

BARCELÓ, A. (2013) «Història i Geografia de la caça» en La caça i la cultura cinegètica de Menorca. (Barceló, A., ed.). Palma. Edición en CD. 12-64. IB / Oc

BARCELÓ, A. (2014) La Caça a Menorca. Palma. Edición en CD. 274 p. IB / L

BARCELÓ, A., BINIMELIS, J. y SEGUÍ. B. (2014) «Cambios en las especies cinegéticas y modalidades de caza en Mallorca entre la década de 1970 y la actualidad» en Pavón, D.; Ribas, A.; Ricart, S.; Roca, A.; Salamaña, I. y Tous, C. (eds.). Actas del XVII Coloquio de Geografía Rural. (Pavón, D., Ribas, A., Ricart, S., Roca, A., Salamaña, I. y Tous, C., eds.) Girona, Documenta Universitaria. Poster temático. http://www.udg.edu/Portals/3/ colorural/Poster\%202_Barcelo_Binimelis_Segui.pdf. IB / Oc

BARCELÓ, A. (2015) Caça, territori i societat a Mallorca. Tesis doctoral. Universitat de les Illes Balears. IB / T

BARCELÓ, A., GRIMALT, M, y BINIMELIS, J. (2015) «Implicaciones territoriales, sociales y ambientales de las sociedades de cazadores locales en Mallorca» en Análisis espacial y representación geográfica: innovación y aplicación. (De la Riva, J., Ibarra, P., Montorio, R. y Rodrigues, M., eds). Zaragoza, XXIV Congreso de la Asociación de Geógrafos de Españoles. Departamento de Geografía y Ordenación de Territorio. Universidad de Zaragoza. 1543-1552. IB / Oc

BRUNET, P. J. (1985) «La caza en las Baleares» El Campo: Servicio de Estudios BBV. Banco Bilbao Vizcaya. Bilbao. 100, 32-34. IB / R

BRUNET, P. J. (1988) «Aspectes geogràfics i socials de la caça i dels vedats a Mallorca» Treballs de geografia: 35 Miscelánea 1978 - 1979, 25-34. IB / R

CAMPOS, M. L. y MORALEDA, C. (1988) «La actividad cinegética como aprovechamiento recreativo del espacio rural de Castilla-La Mancha. La caza Menor en la provincia de Toledo» en El espacio rural de Castilla-La Mancha, T.I, II Reunión de Estudios Regionales de Castilla-La Mancha, 1987. Ciudad Real, Diputación de Ciudad Real, Área de Cultura. 239-250. CLM / Oc

CECILIA, J. A. y MARTÍNEZ GARRIDO, E. (1986) «Manchas de caza mayor: los puestos de montería» Trofeo, 197: 12-16. Esp / RT

CECILIA, J. A. y MARTÍNEZ GARRIDO, E. (1986) Manchas de caza mayor. Madrid, El Viso. 430 p. Esp / L 
CRESPO, J.M. (2013) La caza mayor en la provincia de Jaén (España). Antes de la Ley 1/1970. Análisis Territorial de un recurso natural. Tesis doctoral. Universidad de Jaén. And / T

CRESPO, J.M. (2014) La caza mayor en Jaén antes de la Guerra Civil española. Jaén, Instituto de Estudios Giennenses. 454 p. And / L

FERNÁNDEZ GARCÍA, F. (1985) Las sociedades de cazadores en Asturias. Los cotos de caza privados. Oviedo, Consejería de Agricultura del Principado de Asturias. Ast / L

FERNÁNDEZ GARCÍA, F. (1986) «Las sociedades de cazadores en Asturias. Un ejemplo de las estrategias para la defensa del espacio rural de la invasión urbana» Ería, 10: 143145. Ast / R

FERNÁNDEZ GARCÍA, F. (1991) «La caza en Asturias» Agricultura y Sociedad 58: 241261. Ast / R

FERNÁNDEZ GARCÍA, F. (1992) «La caza» en Geografía de Asturias (Alvargonzález, R.M., Méndez, B. y Morales, G., coords.) Oviedo, Edit. Prensa Asturiana. Vol I, 241-256 Ast / Oc

FERNÁNDEZ GARCÍA, F. y BAJO CUADRADO, F. (2004) «La caza» en Los asturianos. Raíces culturales y sociales de una identidad. (Rodríguez, J., coord.). Oviedo, Edit. Prensa Asturiana, S.A. 233 - 248. Ast / Oc

LÓPEZ ONTIVEROS, A. (1991 b) «Reflexiones y notas sobre la caza en Galicia» Agricultura y Sociedad, 58: 327-338. Gal / R

LÓPEZ ONTIVEROS, A. (1993 b) «Caza, ecología y ética» Revista de Occidente, 149: 90-108. Esp / R

LÓPEZ ONTIVEROS, A. (2003) «La caza en Andalucía» en Geografía de Andalucía. (López Ontiveros, A., coord.). Barcelona, Ariel Geografía. 644-654. And / Oc

LÓPEZ ONTIVEROS, A. (2006) «El Coto de Doñana, espacio geográfico inexplorado y agreste según Chapman y W. J. Buck» en Representaciones culturales del paisaje; y una excursión por Doñana. (Ortega, N., López Ontiveros, A. y Nogué, J., coords.). Madrid, Universidad Autónoma de Madrid, Ediciones de la Universidad Autónoma de Madrid, 261-316. And / Oc

LÓPEZ ONTIVEROS, A., VALLE BUENESTADO, B. y GARCÍA VERDUGO, F. R. (1990) «Los ecologistas españoles se definen ante la caza» Trofeo, 246: 30-31. ESP / Rt

MARTÍNEZ GARRIDO, E. (1982) Estudio geográfico de la caza en el sector de los Yébenes (Toledo). Toledo, Caja de Ahorros Provincial de Toledo. 174 p. CLM / L

MARTÍNEZ GARRIDO, E. (1999) «La evolución reciente de la caza» en Enciclopedia de Castilla - La Mancha (Tamames, R. y Heras, R. coord.). Madrid, Ediciones Corporativas (Edicsa 92). Vol.1, 154-160. CLM / Oc

MARTÍNEZ GARRIDO , E. (1999) «El incremento de las licencias de caza» en Enciclopedia de Castilla - La Mancha (Tamames, R. y Heras, R. coord.). Madrid, Ediciones Corporativas (Edicsa 92). Vol.1, 162. CLM / Oc

OSUNA, R. (1991) «La caracterización de los principales protagonistas de la actividad cinegética en las provincias de Córdoba y Jaén» Agricultura y Sociedad, 58: 339 - 355. And / $\mathbf{R}$

MELCHOR TERRÓN, A. (2003) Los recursos cinegéticos de Extremadura. Badajoz, Universidad de Extremadura. 204 p. Ext / L 
MULERO MENDIGORRI, A. (1987) «Notas sobre la actividad cinegética en las Marismas de Doñana»Ifigea, 3 - 4: 215-226. Ext / R

MULERO MENDIGORRI, A. (1991) «La organización local de la caza en España. Una aproximación geográfica» Agricultura y Sociedad, 58: 187-213. ESP / R

MULERO MENDIGORRI, A. (1995) Espacios rurales de ocio. Significado general y análisis en la Sierra Morena cordobesa. Madrid, Ministerio de Agricultura, Pesca y Alimentación. 584 p. And / L

OBIOL, E. M. (1997) «Geografía de la caza en el País Valenciano» Agricultura y Sociedad, 84: 253-278. PVL / R

SÁNCHEZ, M. J. (1991) «La obra cinegética de A.Chapman y W.J. Buck» Agricultura y Sociedad, 58: 357-372. Esp / R

RENGIFO GALLEGO, J. I. (2012) «Evaluación de la actividad cinegética en Extremadura en los albores del siglo XXI: Retos a corto y medio plazo» Estudios geográficos, Vol. 73 (272) 189-214. Ext / R

SÁNCHEZ, J. D. y ARAQUE, E. (2005) «El parque natural de Despeñaperros: caracterización territorial y perspectivas inmediatas» Cuadernos geográficos, 37: 7-39. And / R

SEGUÍ, B. y BARCELÓ, A. (2004) «Cazas recuperadas de la extinción» Trofeo, 408: 38-40. IB / Rt

UTANDA, L. (1991) «La Caza en el Real Sitio de Aranjuez hasta 1939» en Actas del VI coloquio de geografía rural. (Asociación de Geógrafos Españoles. Grupo de Trabajo de Geografía Rural). Madrid, Universidad Autónoma de Madrid. 247-256. Ma / Oc

\section{Turismo cinegético (13 títulos)}

CECILIA, J. A. y MARTÍNEZ GARRIDO, E. (1989) «La caza, un negocio muy mayor» Expansión, 1013: 40-41. Esp / Rt

LECO, F. (1997) «Potencialidades turísticas de las dehesas extremeñas: la actividad cinegética» en Los turismos de interior: el retorno a la tradición viajera. (Valenzuela, M., coord.). Madrid, Universidad Autónoma de Madrid. 161-168. Ext / OC

LÓPEZ ONTIVEROS, A. y GARCÍA VERDUGO, F. (1987) «Actividad cinegética y turismo en España». en Actas del IV Coloquio Nacional de Geografía Agraria. (Asociación de Geógrafos Españoles). La Laguna, Universidad de la Laguna, A.G.E. Esp / Oc

LÓPEZ ONTIVEROS, A. y VALLE BUENESTADO, B. (1987) «Implicaciones agrarias del turismo cinegético español» en Actas del IV Coloquio Nacional de Geografía Agraria. (Asociación de Geógrafos Españoles). La Laguna, Universidad de la Laguna, A.G.E. 95-106. Esp / Oc

MULERO MENDIGORRI, A. (1991) «Turismo y caza en España. Estado de la cuestión» Agricultura y Sociedad, 58: 147-171. ESP/ R

RENGIFO GALLEGO, J. I. (1993) El turismo en Extremadura. Mérida, Junta de Extremadura. Consejería de Industria y turismo, Depto de Geografía y Ordenación del Territorio, Fundicot y Urvicasa. Cáceres. 397 p. Ext / L

RENGIFO GALLEGO, J. I. (1994) «Aprovechamiento turístico de los recursos naturales de Extremadura» Revista de Extremadura, 14: 63-76. Ext / R 
RENGIFO GALLEGO, J. I. (2008) «La oferta de caza en España en el contexto del turismo cinegético internacional: las especies de caza mayor» Ería (78-79) 53-68. Esp / R

RENGIFO GALLEGO, J. I. (2009) «Un segmento del turismo internacional en auge: el turismo de caza» Cuadernos de Turismo, 22: 187-210. ESP / R

RENGIFO GALLEGO, J. I. (2010 a). «Turismo cinegético» en La Actividad Turística Española en 2009. Oviedo, Asociación Española de Expertos Científicos en Turismo. 437449. ESP / Oc

RENGIFO GALLEGO, J. I. (2010 b) «Usos turísticos de los recursos cinegéticos en la Extremadura del siglo XXI» en Actas del XV Coloquio de Geografía Rural. Territorio, paisaje y patrimonio rural (Leco, F. coord.). Cáceres, Universidad de Extremadura. 31. Ext / Oc

RENGIFO GALLEGO, J. I. (2011) «Una visión general del turismo cinegético» Papeles de Economía Española, 128: 228-236. ESP / R

RENGIFO GALLEGO, J. I., PÉREZ DÍAZ, A. y LECO BERROCAL, F. (2013) «La calidad como mecanismo de diferenciación en el turismo cinegético» en VI Jornadas de Investigación en Turismo. (Jiménez, J.L. y De Fuentes, P., coord.). Sevilla, Universidad de Sevilla. 451-467. ESP / Oc

\section{Otras obras consultadas}

Anuario de Estadística 2012. (2013) Madrid, Ministerio de Agricultura, Alimentación y Medio Ambiente. 1.137 p.

BERNAD, J. (2009) «La caza: un elemento esencial en el desarrollo rural» Mediterráneo económico, 15: 183-203.

BRUNHES, J. (1964) Geografía humana (Edición abreviada por Mme. M. Jean-Brunhes Delamarre y Pierre Deffontaines). Barcelona, Editorial Juventud.

BYE, L. M. (2003) «Masculinity and rurality at play in stories about hunting» Norsk Geografisk Tidsskrift-Norwegian Journal of Geography, 57(3) 145-153.

CECILIA J. A. (1991) «Especies cinegéticas españolas: descripción, modalidades de caza y trofeos» Agricultura y Sociedad, 58: 53-79.

CRESPO, J.M. (En Prensa, 2016) Las intervenciones públicas sobre el recurso caza mayor en la provincia de Jaén (1940-1992). Universidad de Jaén.

CRESPO, J.M. (En Prensa, 2016) «Les 'petites gens' de la chasse au gros gibier dans la Sierra Morena andalouse (1855-1936) le nouvel âge d'or de la vénerie» Bibliothèque du Pôle Rural.

DELIBES, M. (2009) Obras completas V. El cazador. Barcelona, Ediciones Destino. 1.165 p.

ESTRABÓN (1991) Geografía. Madrid, Editorial Gredos. Vol. 1, libros I-II. Introducción general de J. García Blanco; traducción y notas de J.L. García Ramón y J. García Blanco. $560 \mathrm{p}$.

ESTRABÓN (1991) Geografía. Madrid, Editorial Gredos. Vol. 2, libros III-IV. Traducción, introducción y notas de $\mathrm{M}^{\mathrm{a}}$. José Meana y Fèlix Piñero. 220 p.

Garrido, J. L. (2012). La caza. Sector económico. Valoración por subsectores. Madrid, FEDENCA - EEC. 24 p. 
La caza en las autonomías. Trofeo Caza, 480: 92-130.

LEY 45/2007, de 13 de diciembre, para el desarrollo sostenible del medio rural.

MARTÍNEZ-JÁUREGUI, M., ARENAS, C. y HERRUZO, A. C. (2011) «Understanding long-term hunting statistics: the case of Spain (1972-2007)» Forest Systems, 2011, 20 (1) 139-150.

METRA SEIS (1976) Estudio para la evaluación de la contribución de los aprovechamientos cinegéticos a los objetivos de la comunidad nacional. Madrid, Agrupación Nacional de Producción y Aprovechamiento de Especies Cinegéticas. 269 p.

METRA SEIS (1985) Turismo cinegético en España. Madrid, Secretaría General de Turismo, subdirección General de Infraestructura Turística. 276 p.

ØIAN, H. and SKOGEN, K. (2016) «Property and possession: Hunting tourism and the morality of landownership in rural Norway» Society \& Natural Resources, 29(1) 104118.

PITKÄNEN, K., ADAMIAK, C. and HALSETH, G. (2014) «Leisure activities and rural community change: Valuation and use of rural space among permanent residents and second home owners» Sociologia Ruralis, 54(2) 143-166.

RECLÚS, E. (1906-1909) El hombre y la tierra. Barcelona, Escuela Moderna.Volumen I. Versión española, por A. Lorenzo; bajo la revisión de Odón de Buen.

RENGIFO GALLEGO, J. I. y SÁNCHEZ MARTÍN, J.M. (2016) «Caza y espacios naturales protegidos en Extremadura» Investigaciones geográficas, 65: 57-73.

ROSSELLÓ VERGER, V. M. (1964) Mallorca, el Sur y Sureste. Palma de Mallorca, Cámara oficial de comercio, industria y navegación. $553 \mathrm{p}$.

VON ESSEN, E., HANSEN, H. P., KÄLLSTRÖM, H. N., PETERSON, M. N. and PETERSON, T. R. (2015) «The radicalisation of rural resistance: How hunting counterpublics in the Nordic countries contribute to illegal hunting» Journal of Rural Studies, 39 : 199-209.

WOODS, M. (2010) «Performing rurality and practising rural geography» Progress in Human Geography, 34(6) 835-846.

\section{Páginas web}

http://age.ieg.csic.es/geografia_rural/ [Consulta: marzo, 2014]

https://dialnet.unirioja.es/ [Consulta: junio, 2016]

http://etudesrurales.revues.org/ [Consulta: noviembre, 2010]

http://ec.europa.eu/agriculture/rurdev/index_es.htm [Consulta: noviembre, 2010]

http://europa.eu/legislation_summaries/environment/general_provisions/index.es.htm [Consulta: octubre, 2010]

http://etudesrurales.revues.org/ [Consulta: noviembre, 2010]

https://scholar.google.es/ [Consulta: junio, 2016]

http://www.magrama.gob.es/es/biodiversidad/estadisticas/Est_Anual_Caza.aspx [Consulta: marzo, 2014]

http://www.uam.es/departamentos/filoyletras/geografia/descargas/IN\%20MEMORIAM.pdf

Mata Olmo, Rafael. Antonio López Ontiveros, geógrafo andaluz, in memoriam. 2011.

[Consulta: noviembre, 2012] 
FACE. 2013. Women hunters in Europe. Proportion of women hunters in different european countries. http://www.face.eu/about-us/members/european-hunters

FACE. 2010. Hunters in Europe. http://www.face.eu/about-us/members/across-europe/census-of-the-number-of-hunters-in-europe-september-2010

Tesis doctorales: TESEO. https://www.educacion.gob.es/teseo/irGestionarConsulta.do [Consulta: agosto, 2016] 